\title{
FECAL CARRIAGE OF EXTENDED-SPECTRUM BETA-LACTAMASESPRODUCING ESCHERICHIA COLI IN HOSPITALS AND COMMUNITY SETTINGS: A REVIEW
}

\author{
NEHA SHARMA, ANANIA ARJUNA* \\ Department of Medical Laboratory Sciences, Faculty of Applied Medical Sciences, Lovely Professional University, Jalandhar, Phagwara, \\ Punjab, India. Email: anania.arjuna@lpu.co.in
}

Received: 13 April 2017, Revised and Accepted: 22 May 2017

\begin{abstract}
Antibiotic resistance is an emerging threat worldwide, endangering the treatment of serious diseases. Widespread resistance to beta-lactam antibiotics among Gram-negative bacteria (GNB) is a serious threat to the currently used antibacterial therapy. Extended-spectrum beta-lactamases (ESBLs) are a group of enzymes capable of hydrolyzing extended-spectrum cephalosporins and are inhibited by clavulanic acid. These enzymes are a major cause of hospital-acquired infection and community-acquired infections caused by E. coli (Escherichia coli). E. coli forms a part of normal intestinal flora and is an important reservoir of the antibiotic-resistant genes for ESBLs. These resistant antibiotic genes can be easily spread among GNB as these are carried on plasmids. Fecal carriers of ESBL producing E. coli in hospitalized patients and in community can be a reservoir for person-to-person transmission strengthening their dissemination. Over the last few decades, there had been a considerable increase in the emergence and spread of antimicrobial-resistant enzymes favoring the predominance of antibiotic-resistant bacteria which results in morbidity, mortality, and increased hospital expenditure. The gastrointestinal tract plays an important role in development of antibiotic-resistant microorganism and harboring the microorganisms as commensal. Antibiotic consumption may lead to alteration in the genome of the microorganisms leading to emergence of resistant microorganisms. The resistant microorganisms may then spread into the environment through faces aiding dissemination of the resistant genes.
\end{abstract}

Keywords: Morbidity, Mortality, Extended-spectrum beta-lactamases, Escherichia coli.

(C) 2017 The Authors. Published by Innovare Academic Sciences Pvt Ltd. This is an open access article under the CC BY license (http://creativecommons. org/licenses/by/4. 0/) DOI: http://dx.doi.org/10.22159/ajpcr.2017.v10i9.19126

\section{INTRODUCTION}

Resistance to antibiotics has posed a serious threat to both healthcare settings and community. The overuse and misuse of antibiotics has led to the bacteria to counter the effects of antibiotics by developing different resistantstrategies [1]. Amajor consequenceofantibioticselection pressure is the emergence and spread of multidrug-resistant pathogens such as methicillin-resistant Staphylococcus aureus, Metallo-beta-lactamases (MBL) Pseudomonas, vancomycin-resistant S. aureus, extended-spectrum beta-lactamases (ESBLs)-producing bacteria, Klebsiella pneumonia carbapenemase-producing bacteria, vancomycin-resistant Enterococcus, and multidrug-resistant Mycobacterium tuberculosis [2]. Among all these, the ESBL-producing Gram-negative bacteria (GNB) have disseminated across the globe since its first description in 1983 [3].

Beta-lactam antibiotics such as penicillins and cephalosporins work by inhibiting enzymes responsible for the cell wall synthesis of bacteria. Beta-lactam antibiotics were the most common antibiotics used widely to treat infections caused by GNB. An excessive and continuous use of these antibiotics had promoted genetic mutations in the bacteria that benefitted them to expand their activity against several classes of betalactam antibiotics by producing ESBLs [4]. ESBLs are a group of enzymes conferring resistance to beta-lactam ring-containing antibiotics such as penicillins; first-, second-, and third-generation cephalosporins and aztreonam (but not the cephamycins or carbapenems) and are inhibited by beta-lactamase inhibitor such as clavulanic acid, sulbactam, and tazobactam [5]. The genes encoding for ESBLs are located on plasmids and thus can be transferred within and between different bacterial species by transformation, conjugation, or transduction process [6]. The plasmid-mediated transfer of ESBLs has resulted increase resistance to non-beta-lactam antibiotics such as trimethoprim-sulfamethoxazole, aminoglycosides, and fluoroquinolones, tetracyclines as plasmids may carry genes for conferring multidrug resistance presenting an additional challenge for controlling infections caused by ESBLproducing pathogens [7].
Escherichia coli is a GNB commonly found both in pathogenic as well as non-pathogenic feces. The normal commensal $E$. coli may carry genes for antimicrobial resistance that can be transferred to the pathogenic E. coli, so the commensal resistant bacteria of the gut are also a reason for concern as they can be a cause of dissemination of the antibioticresistant genes $[8,9]$.

\section{BETA-LACTAM ANTIBIOTICS: MECHANISM OF ACTION}

Antibiotics have long been considered as the "magic bullet" that would end infectious diseases. They act against bacteria by one of the several ways such as inhibition of cell wall synthesis, inhibition of protein synthesis, impeding nucleic acid synthesis, cell membrane disorganization, or inhibition of a metabolic pathway [10]. Beta-lactam antibiotics include penicillins, cephalosporins, carbapenems, and monobactams. These antibiotics have in common a chemical structure that includes a three-carbon, one-nitrogen cyclic amine structure known as the beta-lactam ring. The side chain associated with the beta-lactam ring is a variable group attached to the core structure by a peptide bond; the side chain variability contributes to antibacterial activity [11]. They act by irreversible inhibition of carboxypeptidases and transpeptidases. These enzymes, also called as penicillin-binding proteins (PBPs) as they can bind irreversibly to the beta-lactam ring, help synthesis of cell wall of bacteria by catalyzing the cross-linking of D-alanine-D-alanine amino acid residues which present in the nascent peptidoglycan layers. Beta-lactam antibiotics share a structural similarity with the D-alanine amino acid residue present in the cell wall. Beta-lactam ring binds to the serine residue of the active site of PBP impeding the binding of $\mathrm{D}$-alanine residue. This irreversible inhibition of PBPs inhibits cell wall synthesis, ultimately resulting in death of bacterial cell by activation of an autolytic system [12,13].

The resistance to beta-lactam antibiotics may be natural or may be acquired through genetic mutations or gene transfer. GNB have developed resistance to beta-lactam antibiotics by producing beta- 
lactam hydrolyzing enzymes called as beta-lactamases and Grampositive bacteria have conferred resistance by producing an altered PBP which is insensitive to beta-lactams [14].

\section{AN INSIGHT INTO THE HISTORY OF ESBLS}

The beginning of antibiotic era with the discovery of penicillin by Alexander Fleming in the year 1928 is marked by the consecutive development of antimicrobial resistance among different pathogens. Alexander Fleming in 1928 observed the growth of a mould of the genus Penicillium inhibiting the growth of bacteria in close vicinity of the mould. He identified that the mould produces an antibacterial substance called penicillin [15]. Even before the introduction of penicillin for the therapeutic use, a bacterial enzyme penicillinase was discovered by Abraham and Chain in 1940. Only after few years of introduction of penicillin for clinical use, penicillin-resistant betalactamases were reported in various Gram-positive and GNB. These beta-lactamases were thought to break down the beta-lactam ring of the antibiotic resulting in ineffective antibiotic [12]. The first plasmidmediated $\beta$-lactamase in GNB was temoniera (TEM)- 1 which was described in the early 1960 s.

To counter the effect of beta-lactamases, broad-spectrum cephalosporin was introduced and they remained the first line of treatment for over 20 years. However, soon after the availability of these antibiotics, enzymes resistant to broad-spectrum cephalosporins emerged known as ESBLs. In 1983, the first report of bacteria producing ESBLs was published. TEM was named so as it was first found in E. coli isolated from the blood of a patient named Temoneira from Greece [5]. In these 20 years, many new antibiotics were developed to treat infections to resist the action of beta-lactamases. However, with the discovery of each new antibiotic, a new class of beta-lactamases has emerged such as the use of broad-spectrum cephalosporins has lead the development of broad-spectrum beta-lactamases (TEM-1, SHV-1) which have emerged as a result of single nucleotide mutation in the TEM or SHV beta-lactamases. Widespread use of third-generation cephalosporins and aztreonam is believed to be the predominant cause of mutations in the earlier discovered broad-spectrum beta-lactamases (TEM, SHV) and has led to the development of ESBLs. The term ESBL was first used by Phillippon, so that they can be differentiated from the broad-spectrum beta-lactamases [16]. By the end of $20^{\text {th }}$ century, many studies have been published studying the recovery of ESBLs from various clinical isolates and in different parts of the world [17]. Some of the studies have also proposed the use of inhibitors of beta-lactamases such as tazobactam for treating infections caused by ESBL-producing bacteria [12].

\section{ESBL-PRODUCING E. COLI IN THE GUT: A SERIOUS THREAT}

Human gastrointestinal tract (GIT) harbors a large number of bacteria, and E. coli forms one of the largest groups, so there is an important role played by the gut in the acquisition and transmission of resistant pathogens [9]. E. coli is a GNB belonging to the family Enterobacteriaceae and colonizes the GIT of the human forming the most abundant facultative anaerobe of the human intestinal microflora. Although E. coli is found as a commensal microorganism in the intestine of human, there are variants of $E$. coli that are pathogenic as well. Pathogenic strains can be classified as intestinal pathogens causing diarrhea and extraintestinal pathogens causing a variety of other infections including urinary tract infections, meningitis, and septicemia [18]. E. coli presents as gut normal microflora may carry antibiotic-resistant genes on plasmids. Pathogenic diarrhea causing strains of E. coli can acquire resistant genes from the commensal $E$. coli in the intestine. Due to the augmented use of antibiotics, the sensitive strains of $E$. coli are killed allowing a more resistant ESBL-producing $E$. coli to survive and grow rapidly to increase in number. These resistant bacteria may then spread to the other person through environment contaminated with faces of these persons [19]. Poor hand hygiene and close contact with the cattle harboring the resistant $E$. coli can be an important contributing factors for the spread of ESBL-producing $E$. coli from a common source or from person to person [20].

\section{CLASSIFICATION OF BETA-LACTAMS AND TYPES OF ESBL}

More than 200 types of ESBL are known till now. There are different schemes for the classification of beta-lactams. The two major classification schemes followed for classifying beta-lactams into different categories are the Ambler molecular classification and the Bush-Jacoby-Medeiros functional classification [21]. Ambler classification scheme divides $\beta$-lactamases into Class A, Class B, Class C, and Class D enzymes on the basis of protein sequence (amino acid similarity). In the Ambler classification scheme, $\beta$-lactamases of Classes A, C. and D are serine $\beta$-lactamases. In contrast, the Class B enzymes are MBL. With the exception of OXA-type enzymes (which are Class D enzymes), the ESBLs are of molecular Class A [3].The majority of ESBLs identified in clinical isolates to date have been SHV or TEM types, which have evolved from narrow-spectrum $\beta$-lactamases such as TEM-1,2 and SHV-1. The Bush-Jacoby-Medeiros classification scheme also called as functional classification scheme classifies beta-lactamase based on substrate and inhibitor profile. According to this scheme, ESBL belongs to the "2be" Group or 2d Group (OXA type ESBL). The 2be designation shows that these enzymes are derived from Group $2 \mathrm{~b}$ beta-lactamases (for example, TEM-1, TEM-2, and SHV-1); the "e" of 2be denotes that the beta-lactamases have an extended spectrum. The ESBLs derived from TEM-1, TEM-2, or SHV-1 differ from their progenitors by as few as one amino acid. This has resulted in a profound change in the enzymatic activity of the ESBLs so that they can now hydrolyze the third-generation cephalosporins or aztreonam, hence the extension of spectrum compared to the parent enzymes [21]. Table 1 shows the Bush Jacoby functional classification and Amber molecular classification of ESBL along with their characteristics.

\section{EPIDEMIOLOGY OF ESBL-PRODUCING E. COLI}

Antimicrobial resistance is rapidly spreading across the globe and entails a significant threat to public health. Antibiotic resistance increases the morbidity, mortality, and costs of treating infectious diseases [22,23]. The gut plays a vital role in the development of antibiotic resistance, and the emergence of resistant microorganisms in the gut may be related to ingestion- or antibiotic-induced alterations in microorganisms. The resistant organisms then contaminate the environment. Asymptomatic fecal carriage of ESBL-producing bacteria had been reported from several countries and continents with wide differences in carriage rates between geographic areas. Over the years, prevalence of ESBL-producing E. coli has increased enormously. Various studies have documented the prevalence and susceptibility of ESBL-producing E. coli, and each one had reported quite different ESBL rates. As mentioned earlier also, ESBLs were first described in 1983 from Germany and England. Various surveys conducted across the region had demonstrated the geographical variation. In a survey of laboratories in the Netherlands, $<1 \%$ of E. coli and K. pneumoniae strains possessed ESBL [24]. While in another study conducted in France and Italy, ceftazidime resistance was observed in as many as $40 \%$ of strains of $K$. pneumonia [25]. The first ESBL-producing organisms were first reported in the US in 1988 [26].

A study conducted in Vietnam observed a prevalence of $87.4 \%$ of GNB from various clinical specimens out of a total 350 isolates. Of these GNB isolates, $88.9 \%$ were Enterobacteriaceae, of which $14.7 \%$ were ESBL-positive [27]. A study conducted by Ko et al., at South Korea, documented $22.4 \%$ of K. pneumoniae isolates and $10.2 \%$ of E. coli isolates as ESBL producers [28]. In a study from India, the percentage of ESBL-positive isolates was found to be elevated, with 23.1\% of isolates being ESBL-positive [29]. Of the isolates from India, $48.4 \%$ of isolates were E. coli and $51.6 \%$ were K. pneumoniae [30]. ESBL prevalence of $30-60 \%$ of from intensive care units in Brazil, Colombia, and Venezuela had been reported [31-34]. Moreover, several studies had been conducted to test the prevalence fecal carriage of ESBL-producing GNB as these carriers can form important reservoirs for the transmission of hospital-acquired infection (HAI) and community-acquired infections caused by these bacteria. In a study conducted at South Africa by Mahomed and Mahomed out of 
Table 1: Bush-Jacoby functional classification and Amber molecular classification

\begin{tabular}{|c|c|c|c|}
\hline $\begin{array}{l}\text { Bush-Jacoby } \\
\text { group }\end{array}$ & $\begin{array}{l}\text { Ambler } \\
\text { class }\end{array}$ & Characteristics & Examples of enzymes \\
\hline 1 & $\mathrm{C}$ & $\begin{array}{l}\text { Cephalosporinases, chromosomal enzymes, resistant to clavulanic } \\
\text { acid }\end{array}$ & E. coli AmpC, P99, ACT-1, CMY-2, FOX-1, MIR-1 \\
\hline $2 \mathrm{a}$ & A & $\begin{array}{l}\text { Penicillinase, greater hydrolysis of benzylpenicillin than } \\
\text { cephalosporins, inhibited by clavulanic acid }\end{array}$ & PC1 \\
\hline $2 b$ & A & $\begin{array}{l}\text { Broad-spectrum beta-lactamases inhibited by clavulanic acid and but } \\
\text { not by EDTA }\end{array}$ & TEM-1, TEM-2, SHV-1 \\
\hline $2 \mathrm{br}$ & A & Penicillinases not inhibited by clavulanic acid and EDTA & TEM-30, SHV-10 \\
\hline 2c & A & $\begin{array}{l}\text { Enzymes hydrolyzing carbenicillin, inhibited by clavulanic acid but } \\
\text { not by EDTA }\end{array}$ & PSE-1, CARB-3 \\
\hline $2 d$ & A & Enzymes hydrolyzing cloxacillin & OXA-1, OXA-10 \\
\hline $2 \mathrm{e}$ & A & $\begin{array}{l}\text { Extended-spectrum } \\
\text { Cephalosporins, inhibited by clavulanic acid but not by aztreonam }\end{array}$ & CepA \\
\hline $2 \mathrm{f}$ & A & Enzymes hydrolyzing carbapenems, inhibited by clavulanic acid & $\begin{array}{l}\text { KPC-2, IMI-1, } \\
\text { SME-1 }\end{array}$ \\
\hline 4 & $\mathrm{D}$ & Miscellaneous enzymes that do not fit into other groups & \\
\hline
\end{tabular}

Table 2: Screening by disc diffusion method

\begin{tabular}{ll}
\hline Antibiotic (mcg) & Diameters of zone of inhibition (mm) \\
\hline Cefpodoxime, 10 & $\leq 17$ \\
Ceftazidime, 30 & $\leq 22$ \\
Cefotaxime, 30 & $\leq 27$ \\
Ceftriaxone, 30 & $\leq 25$ \\
\hline
\end{tabular}

300 samples analyzed, E. coli isolates were obtained from 97 stool samples and $K$. pneumoniae from 12 patients only. ESBL production was positive only in $3 \mathrm{E}$. coli isolates (3.1\%) and 11 isolates out of $12 \mathrm{~K}$. pneumoniae were ESBL-positive. The combined fecal carriage of ESBL-producing E. coli and K. pneumoniae was 4.7\% [35]. Reuland et al. in a study determined the rate of fecal carriage of ESBL-producing Enterobacteriaceae in the Dutch community in the Netherlands. Out of the total 720 samples, 73 of them were tested positive for ESBLproducing Enterobacteriaceae, among which the predominant was E. coli [36]. In contrast, rates reported in Europe never exceeded $10 \%$, with the exception of a recent report of $11.6 \%$ observed in 2011 among patients on admission to a geriatric unit in Belgium. Community carriage in Africa has been studied very poorly. Reported rates appear to be quite high, from $10.0 \%$ in Senegal [37] to $30.9 \%$ in Niger [38]. In a study conducted in a Tertiary Care Hospital in Chennai, India, a high prevalence of ESBL producers was observed. Higher resistance rate was noted for amoxyclav, ciprofloxacin, cefotaxime, ceftazidime, and ertapenem [39]. A study carried out in Coimbatore, India, showed that among 49 isolates, E. coli registered its prevalence in about 44 samples followed by Klebsiella spp. and Pseudomones spp. [40]. Thus, the reported prevalence of carriage of ESBL-producing bacteria may be influenced by characteristics of the population under study such as the geographic area, previous use of antibiotics, and healthcare environment.

\section{PHENOTYPIC METHODS FOR THE DETECTION OF ESBL PRODUCTION IN E. COLI ISOLATES}

Phenotypic detection of ESBL-producing E. coli isolates in clinical laboratory can be done by performing various screening and confirmatory tests according to the guidelines lead by clinical laboratory standard institute [41].

\section{Screening methods for ESBL producers}

Susceptibility of positive E. coli to third-generation cephalosporins is detected by performing antibiotic susceptibility test on Mueller-Hinton agar using a 0.5 McFarland standard inoculum. Screening method for detection of ESBL production is based on measuring the zone of inhibition. E. coli isolates may be regarded as positive for screening test for ESBL production under the following conditions as shown in Table 2.

\section{BROTH MICRODILUTION METHOD}

Broth microdilution test can be performed with Mueller-Hinton broth to determine the minimum inhibitory concentration. A positive test for ESBL-producing $E$. coli isolates is indicated by a MIC $\geq 8 \mu \mathrm{g} / \mathrm{ml}$ for cefpodoxime, MIC $\geq 2 \mu \mathrm{g} / \mathrm{ml}$ for ceftazidime, aztreonam, cefotaxime, or ceftriaxone.

\section{SELECTIVE MEDIUM FOR DETECTION OF ESBL-PRODUCING E. COLI}

Screening can also be made by the use of selective medium such as chrom ID ESBL agar, Brilliance ESBL agar, and HiCrome ESBL agar. ESBL-producing E. coli isolates produce blue-violet colonies on chrom ID ESBL agar and pink to burgundy colonies on Brilliance ESBL agar and either pink or purple colonies on HiCrome ESBL agar.

The isolates showing positive screening test are then tested further by confirmatory methods for ESBL detection as positive screening does not necessarily rule out the production of ESBL.

\section{PHENOTYPIC CONFIRMATORY METHODS FOR THE DETECTION OF ESBL PRODUCTION}

\section{Double disc synergy test}

Standardized inoculums of the test isolate are swabbed on the surface of a Mueller-Hinton agar plate. A combination disc, such as ceftazidime and clavulanic acid $(30 / 10 \mathrm{mcg})$, piperacillin and tazobactam disc $(100 / 10 \mathrm{mcg})$, was placed at the center surface of the plate. Disc containing $30 \mathrm{mcg}$ of ceftazidime, cefotaxime, ceftriaxone, and $10 \mathrm{mcg}$ of cefpodoxime was placed at a distance of $1.8 \mathrm{~cm}$ away from the central disc.

An extension in the zone of inhibition around the peripheral disc toward the centrally placed ceftazidime/clavulanic acid disc indicated ESBL production. An advantage of this method is that the method is relatively simple.

\section{Combined disc test (inhibitor potentiated disc test)}

Cephalosporins disc (cefotaxime $30 \mathrm{mcg}$, ceftazidime $30 \mathrm{mcg}$, and cefpodoxime $30 \mathrm{mcg}$ ) with or without clavulanic acid, $10 \mathrm{mcg}$, was placed on the Mueller-Hinton agar incorporated with the test organism. An increase in the inhibition zone diameter of $\geq 5 \mathrm{~mm}$ in cephalosporins 
Table 3: Worldwide distribution of ESBL-producing Enterobacteriacea

\begin{tabular}{|c|c|c|c|c|c|}
\hline Study group & $\begin{array}{l}\text { Year of } \\
\text { study }\end{array}$ & Study area & Clinical isolates & $\begin{array}{l}\text { ESBL } \\
\text { prevalence (\%) }\end{array}$ & Risk factors \\
\hline Blom et al. [41] & 2016 & Sweden & E. coli & 10 & Foreign travel \\
\hline Asir et al. [42] & 2015 & India & E. coli & 21 & $\begin{array}{l}\text { Invasive devices such as urinary } \\
\text { catheters }\end{array}$ \\
\hline Mahomed and Mahomed [34] & 2014 & South Africa & E. coli and K. pneumoniae & 4.7 & Contaminated food and water \\
\hline Shakya et al. [43] & 2013 & India & E. coli & 9 & Higher socioeconomic status \\
\hline Reuland et al. [35] & 2012 & Netherland & Enterobacteriaceae & 10.1 & Foreign travel \\
\hline Woerther et al. [37] & 2011 & Niger & Enterobacteriaceae & 31 & Transmission from hospitals \\
\hline Peirano et al. [45] & 2011 & Canada & E. coli & 14 & Foreign travel \\
\hline Herindrainy et al. [46] & 2011 & Madagascar & Enterobacteriaceae & 10.1 & Hospital acquisition \\
\hline
\end{tabular}

disc combined with clavulanic acid, compared to cephalosporins alone, indicated ESBL production.

\section{Risk factors for acquisition of ESBL}

The prevalence of ESBLs among clinical isolates varies between countries and from institution to institution. Several studies have already revealed various risk factors associated with colonization and infection with ESBL-producing organisms. In prolonged hospital stay, patients on medical devices such as urinary catheters, and central venous lines have been associated with infections by these organisms. Further, surgical procedures and indiscriminate use of antibiotics are added risk factors for the acquisition of ESBL-producing organisms. Presence of highly resistant pathogens in hospital sewage may result in transmission of resistant bacteria from environment to human.

Table 3 also describes various studies conducted across the world in different years to study the prevalence and the associated risk factors of ESBL-producing E. coli and other GNB.

\section{CONCLUSIONS}

Colonization with multidrug-resistant isolates, including ESBL producing isolates, is one of the significant risk factors for infection. Therefore, importance of detection of carriers of antimicrobial-resistant bacteria in hospitalized patients as well as in community is of utmost value. Antibiotic selection pressure in hospital may be the contributing factor for the presence of large number of carriers harboring resistant bacteria. By minimizing selective pressure through more judicious use of antibiotics, we may well be able to maintain antimicrobial susceptibility patterns at a level and we can tackle with. It was observed that healthy individuals also carried the commensal ESBL-producing E. coli in their gut in a high percentage. The occurrence of these ESBL-positive $E$. coli strains as colonizers in the community indicates a reservoir outside the hospitals that should be taken seriously regarding implementation of screening and hygiene precautions for prevention of infections with these drug-resistant bacteria.

Strict adherence to patient hygiene and infection control practices may be enforced to curtail hospital acquired infections. Rational use of antibiotics would substantially decrease pressure on the gut microflora and thereby limit acquisition of resistant genes among these microorganisms. There is a need to have stringent local and national research and surveillance efforts to monitor resistance pattern of commensal E. coli.

\section{REFERENCES}

1. Ventola CL. The antibiotic resistance crisis: Part 1: Causes and threats. Pharm Ther 2015;40(4):277-83.

2. Rolain JM, Canton R, Cornaglia G. Emergence of antibiotic resistance: Need for a new paradigm. Clin Microbiol Infect 2012;18:615-6.

3. Shaikh S, Fatima J, Shakil S, Rizvi SM, Kamal MA. Antibiotic resistance and extended spectrum beta-lactamases: Types, epidemiology and treatment. Saudi J Biol Sci 2015;22(1):90-101.

4. Kong KF, Schneper L, Mathee K. Beta-lactam antibiotics: From antibiosis to resistance and bacteriology. APMIS Actapathol Microbiol Etimmunol Scand 2010;118(1):1-36.

5. Paterson DL, Bonomo RA. Extended-spectrum $\beta$-lactamases: A clinical update. Clin Microbiol Rev 2005;18(4):657-86.

6. Vaidya VK. Horizontal transfer of antimicrobial resistance by extendedspectrum $\beta$ lactamase-producing Enterobacteriaceae. J Lab Phys 2011;3(1):37-42

7. Lagacé-Wiens PR, Nichol KA, Nicolle LE, Decorby MR, McCracken M, Alfa MJ, et al. ESBL genotypes in fluoroquinoloneresistant and fluoroquinolone-susceptible ESBL-producing Escherichia coli urinary isolates in Manitoba. Can J Infect Dis Med Microbiol 2007;18(2):133-7.

8. Philippon A, Labia R, Jacoby G. Extended-spectrum beta-lactamases. Antimicrob Agents Chemother 1989;33:1131-6.

9. Huddleston JR. Horizontal gene transfer in the human gastrointestinal tract: Potential spread of antibiotic resistance genes. Infect Drug Resist 2014; 7:167-76.

10. Levy SB, Marshall B. Antibacterial resistance worldwide: Causes, challenges and responses. Nat Med 2004;10:S122-9.

11. Murray B. New aspects of antimicrobial resistance and the resulting therapeutic dilemmas. J Infect Dis 1991;163:1185.

12. Drawz SM, Bonomo RA. Three decades of $\beta$-lactamase inhibitors. Clin Microbiol Rev 2010;23(1):160-201.

13. Spratt BG. Properties of the penicillin-binding proteins of Escherichia coli K12. Eur J Biochem 1977;72(2):341-52.

14. Chambers HF. Penicillin-binding protein-mediated resistance in pneumococci and staphylococci. J Infect Dis 1999;179 Suppl 2:S353-9.

15. Aminov RI. A brief history of the antibiotic era: Lessons learned and challenges for the future. Front Microbiol 2010;1:134.

16. Bradford PA. Extended-spectrum $\beta$-lactamases in the $21^{\text {st }}$ century: Characterization, epidemiology, and detection of this important resistance. Threat Clin Microbiol Rev 2001;14(4):933-51.

17. Rawat $\mathrm{D}$, Nair D. Extended-spectrum $\beta$-lactamases in gram negative bacteria. J Glob Infect Dis 2010;2(3):263-74.

18. Katouli M. Population structure of gut Escherichia coli and its role in development of extra-intestinal infections. Iran J Microbiol 2010;2(2):59-72

19. Carlet J. The gut is the epicentre of antibiotic resistance. Antimicrob Resist Infect Control 2012;1(1):39.

20. Brolund A. Overview of ESBL-producing Enterobacteriaceae from a nordic perspective. Infect Ecol Epidemiol 2014;4. DOI: 10.3402/iee. v4.24555.

21. Bush K, Jacoby GA. Updated functional classification of $\beta$-lactamases. Antimicrob Agents Chemother 2010;54(3):969-76.

22. Rice LB. The clinical consequences of antimicrobial resistance. Curr Opin Microbiol 2009;12(5):476-81.

23. Davies J, Davies D. Origins and evolution of antibiotic resistance. Microbiol Mol Biol Rev 2010;74(3):417-33.

24. Stobberingh EE, Arends J, Hoogkamp-Korstanje JA, Goessens WH, Visser MR. Occurrence of extended-spectrum beta lactamases in Dutch hospitals. Infection 1999;27:348-54.

25. Branger C, Lesimple AL, Bruneu B, Berry P, Lambert-Zechovsky N. A long-term investigation of the clonal dissemination of Klebsiella pneumoniae isolates producing extended-spectrum beta lactamases in a university hospital. J Med Microbiol 1998;47:201-9.

26. Jacoby GA. Extended-spectrum $\beta$-lactamases and other enzymes providing resistance to oxyimino $\beta$-lactams. Infect Dis Clin N Am 1997; 11:875-87.

27. Jones SL, Nguyen VK, Nguyen TM, Athan E. Prevalence of 
multiresistant gram-negative organisms in a surgical hospital in Ho Chi Minh city, Vietnam. Trop Med Int Health 2006;11:1725-30.

28. Ko KS, Lee MY, Song JH, Lee H, Jung DS, Jung SI, et al. Prevalence and characterization of extended-spectrum beta-lactamase producing Enterobacteriaceae isolated in Korean hospitals. Diagn Microbiol Infect Dis 2008;61:453-9.

29. Varaiya AY, Dogra JD, Kalkarni MH, Bhalekar PN. Extended-spectrum beta-lactamase-producing Escherichia coli and Klebsiella pneumonia in diabetic foot infections. Indian J Pathol Microbiol 2008;51:370-2.

30. Mendes C, Hsiung A, Kiffer C, Oplustil V, Sinto S, Sampaio J, et al. Evaluation of the in vitro activity of 9 antimicrobials against bacterial strains isolated from patients in intensive care units in Brazil: MYSTIC antimicrobial surveillance program. Braz J Infect Dis 2000;4:236-44.

31. Otman J, Cavassin ED, Perugini ME, Vidotto MC. An outbreak of extended-spectrum beta-lactamase-producing Klebsiella species in a neonatal intensive care unit in Brazil. Infect Control Hosp Epidemiol 2002;23:8-9.

32. Pfaller MA, Jones RN, Doern GV. Multicenter evaluation of the antimicrobial activity for six broad-spectrum beta-lactams in Venezuela: Comparison of data from 1997 and 1998 using the etest method. Venezuelan antimicrobial resistance study group. Diagn Microbiol Infect Dis 1999;35:153-8.

33. Pfaller MA, Jones RN, Doern GV, Salazar JC. Multicenter evaluation of antimicrobial resistance to six broad-spectrum betalactams in Colombia: Comparison of data from 1997 and 1998 using the Etest method. The Colombian antimicrobial resistance study group. Diagn Microbiol Infect Dis 1999;35:235-41.

34. Mahomed S, Mahomed Y. Faecal carriage of extended spectrum betalactamase producing Escherichia coli and Klebsiella pneumoniae in children from the community of Kwadedangendlale, KwaZulu-Natal, South Africa. Int J Infect Control 2014;11:3.

35. Reuland EA, Overdevest IT, Al-Naiemi N, Kalpoe JS, Rijnsburger MC, Raadsen SA, et al. High prevalence of ESBL-producing Enterobacteriaceae carriage in Dutch community patients with gastrointestinal complaints. Clin Microbiol Infect 2013;19(6):542-9.

36. Ruppe E, Woerther PL, Diop A, Sene AM, da Costa A, Arlet G, et al. Carriage of CTX-M-15-producing Escherichia coli isolates among children living in a remote village in Senegal. Antimicrob Agents
Chemother 2009;53:3135-7.

37. Woerther PL, Angebault C, Jacquier H, Hugede HC, Janssens AC, Sayadi $\mathrm{S}$, et al. Massive increase, spread, and exchange of extended spectrum $\beta$-lactamase-encoding genes among intestinal Enterobacteriaceae in hospitalized children with severe acute malnutrition in Niger. Clin Infect Dis 2011;53:677-85.

38. CLSI. Performance Standards for Antimicrobial Susceptibility Testing; Twenty-First Informational Supplement. CLSI Document M100-S21. Wayne, PA: Clinical and Laboratory Standards Institute; 2011.

39. Sanidhya R, Priya RL, Selvam E. Antibiotic susceptibility pattern and ESBL prevalence in Escherichia coli isolates from pus samples in a tertiary care hospital. Int J Pharm Pharm Sci 2015;7(3):263-4.

40. Muraleetharan M, Vishwanathan T. Epidemiological studies on varying extended spectrum beta lactamase-producing uropathogenic bacteria. Int J Pharm Pharm Sci 2014;6(11):57-60.

41. Blom A, Ahl J, Månsson F, Resman F, Tham J. The prevalence of ESBLproducing Enterobacteriaceae in a nursing home setting compared with elderly living at home: A cross-sectional comparison. BMC Infect Dis 2016;16:111.

42. Asir J, Nair S, Devi S, Prashanth K, Saranathan R, Kanungo R. Simultaneous gut colonisation and infection by ESBL-producing Escherichia coli in hospitalised patients. Acad Manage J 2015;8(6):200-7.

43. Shakya P, Barrett P, Diwan V, Marothi Y, Shah H, Chhari N, et al. Antibiotic resistance among Escherichia coli isolates from stool samples of children aged 3 to 14 years from Ujjain, India. BMC Infect Dis 2013;13:477.

44. Wickramasinghe NH, Xu L, Eustace A, Shabir S, Saluja T, Hawkey PM, et al. High community faecal carriage rates of CTX-M ESBL-producing Escherichia coli in a specific population group in Birmingham, UK. J Antimicrob Chemother 2012;67(5):1108-13 .

45. Peirano G, Laupland KB, Gregson DB, Pitout JD. Colonization of returning travelers with CTX-M-producing Escherichia coli. J Travel Med 2011;18:299-303.

46. Herindrainy P, Randrianirina F, Ratovoson R, Hariniana ER, Buisson Y, Genel N, et al. Rectal carriage of extended-spectrum beta-lactamaseproducing gram-negative bacilli in community settings in Madagascar. PLoS One 2011;6(7):e22738 